\title{
Application Research on Gradient Utilization of Geothermal Water in a Heating Process
}

\author{
Jianli LIU ${ }^{1, a}$, Meng $\mathrm{SI}^{2, \mathrm{~b}}$ \\ ${ }^{1}$ Bohai Oil Water and Power Service Company, Donggu Oil New Village, Binhai New Area, Tianjin \\ 300452, China \\ ${ }^{2}$ School of Energy and Environmental Engineering, Hebei University of Technology, Tianjin 300401, \\ China \\ acCorresponding author email: liujianli998@sina.com, bemail: 1253757136@qq.com
}

Keywords: Geothermal Water; Gradient Utilization; Heat Supply

\begin{abstract}
Geothermal water is a material widely used to provide thermal energy for heating supply in China. To protect the water resource, save energy and ensure the sustainable economic development, more attention must be paid to reach the rational utilization of the geothermal water. In this paper, gradient utilization of the geothermal water in Donggu area in Tianjin China is studied with the analysis of the heating operation case of the heating control center in Donggu. Analysis results show that, both the direct geothermal supply at the beginning and the end of the heating and the direct geothermal supply combined adjusting heat by the heat pump in the middle of the heating alleviate the shortage situation of the heating water source in Donggu area by the gradient utilization of the geothermal tail water. In this way, the stability of the heating is ensured, and it meets the heating temperature requirements. And the purposes of saving energy, reducing consumption and protecting the resources are achieved.
\end{abstract}

\section{Introduction}

Geothermal energy has become a kind of groundwater resource which cannot be ignored[1] and it has low emission and energy generation cost[2-3]. However, it is not taken from the inexhaustible. Generally, geothermal energy is used for electricity generation and direct usage[4-5]. Some scholars also found that novel cogeneration system can make the best of geothermal resources[6-9]. In this paper, gradient utilization of the geothermal water in Donggu area in Tianjin is studied. The heating system in Donggu area is divided into industrial and civil heating system. There are 9 Guantao geothermal wells in Donggu area, including 5 extraction wells where the water is about $70^{\circ} \mathrm{C}$. Wells used in the heating dispatching center are three Guantao wells (1th, 5th and 9th east wells), three Guantao recharge wells and 6th well in Minghua town group( the water is about $39^{\circ} \mathrm{C}$ ). At present, the production ability of the three Guantao wells is basically between 85 to $100 \mathrm{~m}^{3} / \mathrm{h}$, and it is about $50 \mathrm{~m}^{3} / \mathrm{h}$ for the 6 th well in Minghua town group. That is, the total production ability of the 4 wells is 305 to $350 \mathrm{~m}^{3} / \mathrm{h}$. While the circulating water needed in the heating dispatching center is about $400 \mathrm{~m}^{3} / \mathrm{h}$, and there is a lack of 50 to $95 \mathrm{~m}^{3} / \mathrm{h}$ water. Therefore the gradient utilization of the geothermal water must be taken into account. As the temperature requirements of the civil $\left(18 \pm 2^{\circ} \mathrm{C}\right)$ and the industrial $\left(16 \pm 2^{\circ} \mathrm{C}\right)$ are different, and the heating system can be divided into two levels, which makes the gradient utilization of the geothermal tail water feasible.

There is a new added apartment building of 23000 square meters in the 6th area of Lanyuan in Donggu, and it requires to be heated in the winter. Based on the shortage of the geothermal water, a proposal, that changes the original wall heating method into floor heating way so that the geothermal water can be better used, is put forward.

A pipeline of DN 200 is educed from the recharge pipeline of the 4th well and it is used as a special water resource line for the heating supply water of the apartment building. Therefore, the backwater of the civil system at the beginning and the end of the heating can not only fill water for the industrial system, but also can supply water for the new apartment building by the recirculation 
pump. And after the heat transfer in the apartment building, the backwater recharges into the 4th well as the recharge water resource.

Performance coefficient of heat pump (COP) is an index which measures the heating effect and power consumption of the heat-pump unit. The higher COP is, the better the heating effect is, and the power consumption is less. On the contrary, lower COP indicates worse heating effect and more power consumption. The calculation method of COP is as follows:

$$
\begin{aligned}
& \mathrm{COP}=\frac{\mathrm{Q}}{\mathrm{W}} \\
& \mathrm{Q}=\mathrm{c} \cdot \mathrm{m} \cdot \Delta \mathrm{t} \\
& \Delta \mathrm{t}=\mathrm{t}_{1}-\mathrm{t}_{2}
\end{aligned}
$$

where, $\mathrm{Q}$ is the heating effect of pump, $\mathrm{w}$; $\mathrm{W}$ represents the power consumption of pump, w; $\mathrm{C}$ refers to the specific heat capacity of water, $\mathrm{J} /\left(\mathrm{kg} \cdot{ }^{\circ} \mathrm{C}\right) ; \mathrm{m}$ is water quality, $\mathrm{kg} ; \mathrm{t}_{1}$ represents water-supply temperature of heat pump, ${ }^{\circ} \mathrm{C} ; \mathrm{t}_{2}$ refers to backwater temperature of heat pump, ${ }^{\circ} \mathrm{C}$

Considering that geothermal water has no significant changes after heating users and water-supply temperature of heat pump $t_{1}$ is constant, lower backwater temperature $t_{2}$ can get a great heating effect $\mathrm{Q}$, that makes COP higher and heating effect better, so the use of geothermal energy is more fully.

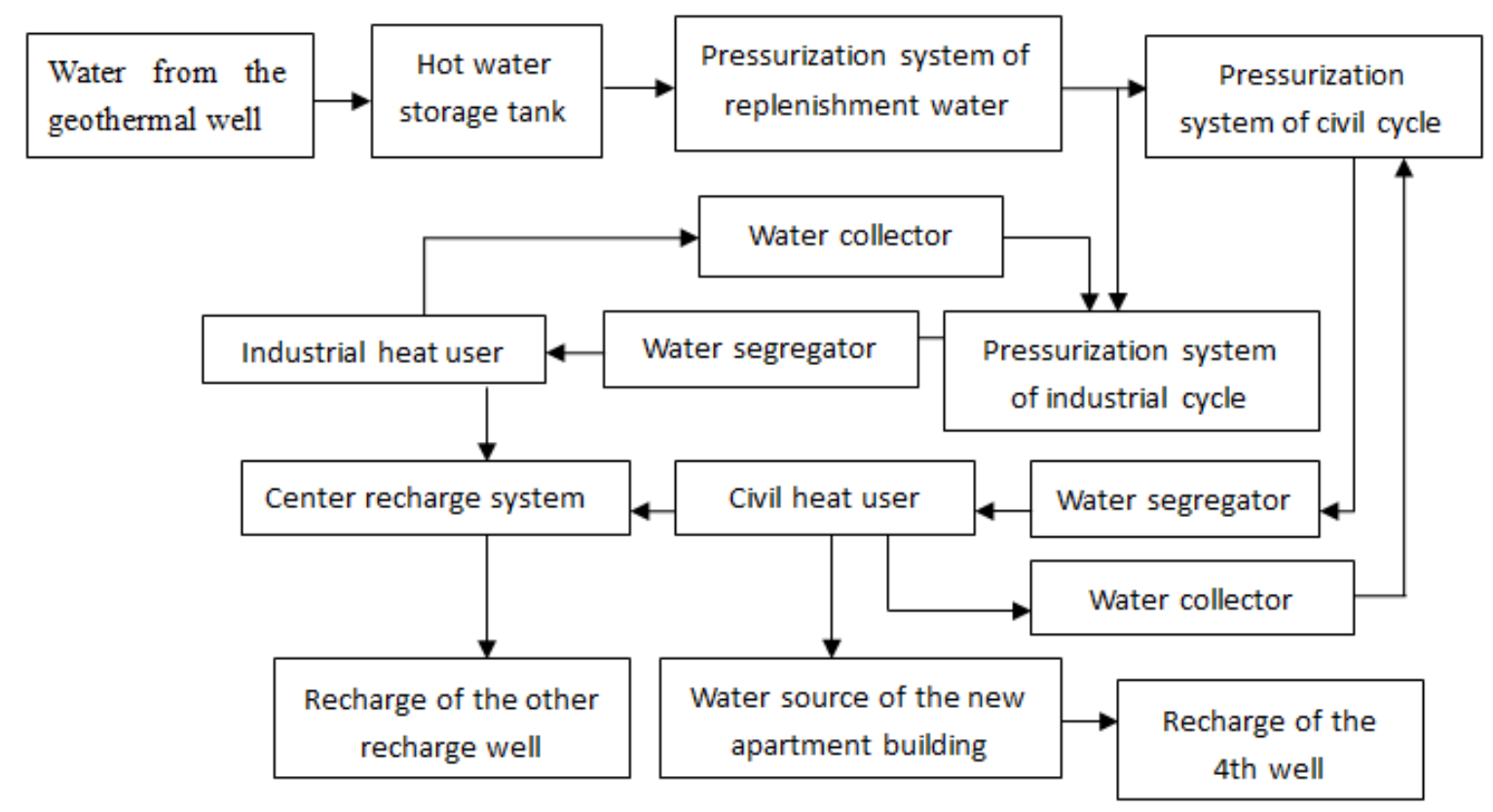

Fig.1. Heat supply process at the beginning and the end of the heating

\section{Heat Supply System at the Beginning and the End of the Heating}

At the beginning and the end of the heating, the outdoor minimum temperature is above $-3^{\circ} \mathrm{C}$, and direct heat supply mode is adopted in this stage. Heat supply process is shown in Fig.1. Most extractive water at high temperature $\left(70^{\circ} \mathrm{C}\right)$ flows into civil heating system for the circular heating, and the cycling backwater is collected by the water collector. A little part of the water $\left(70^{\circ} \mathrm{C}\right)$ remained is used as the supplement in order to adjust the heat peak for the industrial system. Part of the cycling backwater at $30^{\circ} \mathrm{C}$ from the industrial system enters into the water tank of low temperature and flows into the recharge well by the recharge devices so that the geothermal resource is protected. The other part of the water $\left(30^{\circ} \mathrm{C}\right)$ remained is used for the cycling heat supply in the industrial system. For part of the cycling backwater $\left(45^{\circ} \mathrm{C}\right)$ of the civil system, it is used as the heat source water for the new apartment building and the heat which is equivalent to $10^{\circ} \mathrm{C}$ is extracted, and the backwater at $35^{\circ} \mathrm{C}$ flows directly into the 4 th recharge well by the recharge 
device. The other part of the cycling backwater $\left(45^{\circ} \mathrm{C}\right)$ of the civil system, which is used as the replenishment water of the industrial system, enters into the pressurization system of the industrial cycle to heat the system. The rest of the cycling backwater $\left(45^{\circ} \mathrm{C}\right)$ of the civil system continues to heat the civil system.

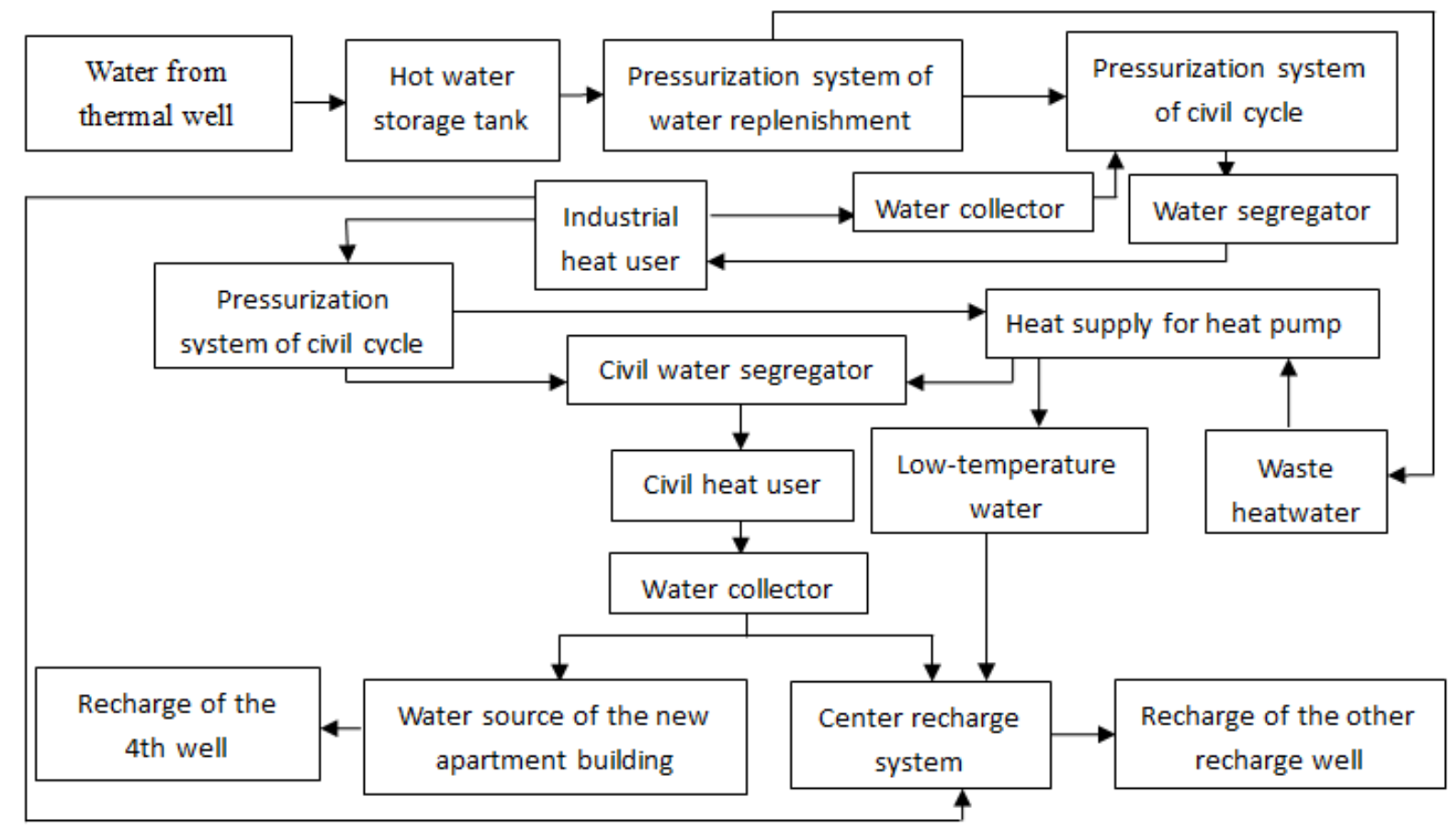

Fig.2. Heat supply system in the middle of the heating

\section{Heat Supply System in the Middle of the Heating}

Different heat supply systems adopt different heat supply modes in the middle of the heating. Heat supply process in the middle of the heating is shown in Fig.2. For the industrial system, direct geothermal supply mode is applied and the extracted hot geothermal water $\left(70^{\circ} \mathrm{C}\right)$ directly enters into the heat supply system of the industrial cycle through the pressurization system. And part of the cycling backwater $\left(40^{\circ} \mathrm{C}\right)$ of the industrial system mixes with the hot geothermal water $\left(70^{\circ} \mathrm{C}\right)$ so that the temperature of the water becomes $50^{\circ} \mathrm{C}$, and then continues to supply heat for the industrial system. While the other part of the cycling backwater $\left(40^{\circ} \mathrm{C}\right)$ of the industrial system enters into the water tank of medium temperature and mixes with the backwater of the civil system, and the temperature of the mixed water becomes $45^{\circ} \mathrm{C}$. Then it is used as the waste hot water of the heat pump and participates in the heat supply process of the civil system. For the civil system, the mode of the direct geothermal supply combined adjusting heat by the heat pump is adopted. Part of the cycling backwater $\left(50^{\circ} \mathrm{C}\right.$ ) of the civil system is heated to $65^{\circ} \mathrm{C}-70^{\circ} \mathrm{C}$ by the heat pump and enters into the cycling system of the civil heat supply. And it mixes with the cycling backwater $\left(50^{\circ} \mathrm{C}\right)$ in the water segregator and then enters into the civil heat supply system to supply heat. Part of the cycling backwater $\left(50^{\circ} \mathrm{C}\right)$ enters into the water tank at medium temperature and mixes with the cycling backwater $\left(40^{\circ} \mathrm{C}\right)$ of industrial system, little part of extracted hot geothermal water $\left(70^{\circ} \mathrm{C}\right)$ and low-temperature water $\left(25^{\circ} \mathrm{C}-30^{\circ} \mathrm{C}\right)$ from waste hot water after the heat transfer process of the heat pump, and then becomes mixed water at $45^{\circ} \mathrm{C}$ and used as waste hot water of the heat pump. The heat of part of the water at $45^{\circ} \mathrm{C}$, which is equivalent to $20^{\circ} \mathrm{C}$, is extracted and is used to heat the backwater at $50^{\circ} \mathrm{C}$ and makes its temperature increased to $65^{\circ} \mathrm{C}-70^{\circ} \mathrm{C}$, and then is sent to the 
civil heating system for the cycling heating. The waste hot water of the heat pump at $45^{\circ} \mathrm{C}$ becomes low-temperature water at $25^{\circ} \mathrm{C}-30^{\circ} \mathrm{C}$ after the heat extracted, and then is collected into the water tank of low temperature and is recharged by the recharge device. Part of the mixed water at $45^{\circ} \mathrm{C}$ is used as the water source of the apartment building and heat which is equivalent to $10^{\circ} \mathrm{C}$ is extracted. After the heating exchange process, backwater at $35^{\circ} \mathrm{C}$ flows into the 4th recharge well.

In this way, gradient utilization of the geothermal water is adopted in the whole heating period, which alleviates the tense situation of the shortage of the geothermal water in Donggu area and it meets the heating requirement of the new apartment building. With the effective use of the geothermal water, the heat of the geothermal water is extracted at the greatest extent.

\section{Conclusion}

Both the direct geothermal supply at the beginning and the end of the heating, and the direct geothermal supply combined adjusting heat by the heat pump in the middle of the heating alleviate the shortage situation of the heating water source in Donggu area by adopting the effective method, that is, gradient utilization of the geothermal water. The stability of the heating is ensured, and it meets the heating temperature requirements. And the targets of saving energy, reducing consumption and protecting the resources are obtained.

\section{Acknowledgement}

In this paper, the research was sponsored by the Bohai Oil Water and Power Service Company, Tianjin China.

\section{References}

[1] S.A. Ghoreishi-Madiseh, F. Hassani, F. Abbasy. Numerical and experimental study of geothermal heat extraction from backfilled mine stopes[J]. Applied Thermal Engineering, 2014(1) 1-12.

[2] C.O. Popiel, J. Wojtkowiak, B. Biernacka. Measurements of temperature distribution in ground[J]. Experimental Thermal and Fluid Science, 2001(25) 301-309.

[3] N. Johnstone, I. Hascic, D. Popp, Renewable energy policies and technological innovation: evidence based on patent counts[J]. Environmental Resource Economics, 2010(45)133-155.

[4] Byoung Ohan Shim, Youngmin Lee, Chan-Hee Park. Numerical model of the low temperature geothermal area for direct use in Pohang, South Korea[J]. Procedia Earth and Planetary Science, 2013(7) 802-805.

[5] Jean-Louis Fannou, Clément Rousseau, Louis Lamarche, Kajl Stanislaw. Experimental analysis of a direct expansion geothermal heat pump in heating mode[J]. Energy and Buildings, 2014(75) 290-300.

[6] Tailu Li, Jialing Zhu, Shouliang Xin, Wei Zhang. A novel geothermal system combined power generation, gathering heat tracing, heating/domestic hot water and oil recovery in an oilfield[J]. Geothermics, 2014(51) 388-396.

[7] Sun, Z.G. Energy efficiency and economic feasibility analysis of cogeneration system driven by gas engine[J]. Energy Build. 2008(40) 126-130.

[8] Havelsky, V. Energetic efficiency of cogeneration systems for combined heat, cold and power production[J]. International Journal of Refrigeration, 1999(22) 479-485.

[9] Matelli, J.A., Bazzo, E., da Silva, J.C. Development of a case-based reasoning prototype for cogeneration plant design[J]. Applied Energy, 2011(88) 3030-3041. 